\title{
Acute short-term multimodal treatment for newly arrived traumatized refugees: Reflections on the practical experience and evaluation
}

\author{
Mechthild Wenk-Ansohn, ${ }^{* 1}$, Carina Heeke, ${ }^{*}, * * 1$, Maria Böttche, ${ }^{*}, *$, \\ Nadine Stammel***
}

Key points of interest:

- A multimodal short-term treatment program of approximately six months was developed including psychotherapy, social work, group therapy and psychiatric treatment modules for newly arrived refugees who experienced trauma-related symptoms after recent traumatization in their home country and/or during their flight.

- Improvements in symptom severity could be achieved despite the extremely high symptom load at the beginning of treatment, uncertainties regarding residence status, and the often unstable living conditions.

- In addition to psychotherapy, newly arrived refugees need comprehensive social work and counselling for legal aspects in order to deal with difficulties regarding their asylum applications.

\footnotetext{
*) Center ÜBERLEBEN, Berlin, Germany

$\star \star)$ Freie University Berlin, Department of ClinicalPsychological Intervention, Germany

${ }^{1}$ Shared first authorship.

Correspondence to: m.wenk-ansohn@ueberleben.org
}

\begin{abstract}
Background: A short-term multimodal acute treatment program of approximately six months' duration for newly arrived refugees at Center ÜBERLEBEN (Berlin Center for Torture Victims) was developed. The purpose of this study was to evaluate this program by examining changes in PTSD, anxiety and depression symptom severity after treatment, and to reflect on practical experiences in carrying out the program. Methods: At the beginning (T1) and following completion of the shortterm treatment program (T2) patients in a single-group design were assessed with the Posttraumatic Stress Disorder Checklist for PTSD and the Hopkins-Symptom Checklist for depression and anxiety (perprotocol analysis). Results: Of the 92 patients who completed T1, 44 completed T2 assessments. Medium to large effect sizes were found for reductions in overall PTSD $(d=0.88)$, depression $(d=0.83)$, and anxiety symptoms $(d=0.67)$. While at the beginning of treatment (T1) $97.7 \%(n=43)$ fulfilled diagnostic criteria for both PTSD and depression, and $95.5 \%(\mathrm{n}=42)$ for anxiety, at T2, 70.5\% $(\mathrm{n}=31)$ fulfilled the criteria for clinically relevant PTSD, 79.5\% $(n=35)$ for depression and $70.5 \%(n=31)$ for anxiety. Discussion: Despite the high symptom load at the beginning of treatment, uncertainties regarding residence status, and
\end{abstract}


the unstable living conditions, patients seem to benefit from the multidisciplinary shortterm treatment. This study adds preliminary evidence to the efficacy of multimodal treatment and suggests that improvements in symptom severity can be achieved within the often extremely stressful period after arrival. Keywords: Refugees, asylum seekers, trauma, multidisciplinary, short-term treatment, stepped care, early interventions, PTSD

\section{Introduction}

Global forced displacement has increased and many people flee their homes due to war, armed conflict, torture and other systematic human right violations. Current estimates project that there are 65 million refugees, most of which are internally displaced persons (UNHCR, 2016). In 2015 and 2016, altogether $1,164,269$ asylum requests were submitted to the German Federal Agency of Migration and Refugees with $36.5 \%$ of asylum applicants coming from Syria, $13.6 \%$ from Afghanistan, and $10.8 \%$ from Iraq (Bundesamt für Migration und Flüchtlinge [German Federal Agency of Migration and Refugees], 2017). In addition to the potentially traumatic experiences in their home countries, refugees are often confronted with further potentially traumatic experiences during their flight and ongoing stressors in their host country (Lambert \& Alhassoon, 2015). The traumatization is often experienced sequentially (i.e. before, during and after the flight), increasing the risk for the development of severe mental health problems, such as posttraumatic stress disorder (PTSD) or depression (Bogic, Njoku, \& Priebe, 2015; Fazel, Wheeler, \& Danesh, 2005). Average rates of $25-30 \%$ for PTSD and $30-43 \%$ for depression have been reported among populations exposed to mass conflict and displacement (Chung et al., 2018; Slewa-
Younan, Uribe Guajardo, Heriseanu, \& Hasan, 2015; Steel et al., 2009; Tinghög et al., 2017). For refugees in Germany, PTSD rates between $18 \%$ and $40 \%$ and for depression between $22 \%$ and $55 \%$ have been reported (Butollo \& Maragkos, 2012; Führer, Eichner, \& Stang, 2016; Gäbel, Ruf, Schauer, Odenwald, \& Neuner, 2006; Richter, Lehfeld, \& Niklewski, 2015).

Due to a lack of representative studies in Germany, the findings in these studies were only preliminary.

A number of factors can affect the complexity and severity of a mental disorder after trauma, such as the gravity and duration of the trauma, the number of cumulative traumatic events, experiences associated with feelings of shame and guilt, few personal resources to deal with and compensate the trauma, as well as the situational context after the traumatic event (Brewin et al., 2017; Herman, 1992; WenkAnsohn, 2017).

Post-migration stressors such as problems with the asylum process or difficult living conditions may hinder refugees to feel safe in their host country and therefore aggravate psychological disorders. Several studies demonstrated that the extent of post-migration stressors was associated with psychological distress (Nickerson, Schick, Schnyder, Bryant, \& Morina, 2017; Schweitzer, Melville, Steel, \& Lacherez, 2006). These studies also suggested that refugees who have been traumatized in the past may have a greater vulnerability to develop adverse mental health outcomes such as PTSD when confronted with postmigration stressors.

Depending on their experiences prior, during and after their flight, refugees may suffer not only from PTSD or depression, but also from adjustment disorders, suicidal tendencies, somatic symptom 
disorders, anxiety, impulse control disorders, severe dissociative disorders, substance abuse, prolonged grief, or even enduring personality change after catastrophic experiences (Priebe, Giacco, \& El-Nagib, 2016). Additionally, pre-existing or newly developed physical illnesses due to stress might develop or become more aggravated (Gurris \& Wenk-Ansohn, 2013).

Although refugees are at high risk of psychological impairment, their access to the German health-care system is initially restricted (Bozorgmehr \& Razum, 2015). Even when after 15 months this structural restriction to the welfare system is lifted, the lack of interpreters and resulting communication difficulties often impede access to adequate care. Specialized psychosocial centers offer comprehensive care and treatment, taking into account the diverse problems faced by refugees. However, these centers usually have limited capacities and are not available in every part of Germany. As a result, the mental health care provision in Germany, as well as in other European countries, is insufficient, leaving a great number of refugees without necessary treatment (Bozorgmehr \& Razum, 2015). Figures for 2015 show that an estimated 379,848 refugees were in need of mental health treatment in Germany, but only about $5 \%$ actually received treatment (Bundesweite Arbeitsgemeinschaft der psychosozialen Zentren für Flüchtlinge und Folteropfer (BAfF) [German Network of Rehabilitation Centres for Refugees and Survivors of Torture], 2016). Thus, many traumatized refugees did not find access to the regular mental healthcare system during the vulnerable period after arrival in the host country.

Depending on the needs of the patients as well as on the locally existing mental health care structures, stepped care approaches seem generally useful to adequately meet the demand and to ensure an overall better health care provision for this patient group and to offer care as soon as possible. Figure 1 displays the various levels of an intervention pyramid for traumatized refugees adapted from the intervention pyramid for humanitarian catastrophes (IASC Guidelines, InterAgency Standing Committee, 2007) and adjusted to the conditions of a developed health care system in Western host countries (see Wenk-Ansohn, 2017). A transfer from one level to the next is possible, depending on the needs of the survivors over time similar to a "stepped care-model" (see NICE-Guidelines for PTSD, National Institute for Health and Care Excellence (NICE), 2005).

Adequate material and social reception conditions for refugees form a basic requisite in order for medical and psychotherapeutic measures to be effective. In the European Reception Directive (Art. 19 Par. 2 RL 2013/33/EU, European Union, 2013), consideration and care for the special needs of vulnerable groups is demandedbut many European countries are yet to implement this guideline (CIR Rifugiati, 2017; Leisering, 2018).

\section{Specialized care}

Specialized centers for the medical and psychosocial rehabilitation for victims of war and torture (in Germany organized under the umbrella organization BAfF) offer comprehensive care and treatment for refugees who are victims of warrelated violence, torture or other human rights violations. This is mostly realized with a multidisciplinary and multimodal approach, which differs to a large extent from out-patient primary care provided by hospitals and resident psychiatrists or 
Figure 1: Elements of adequate health care

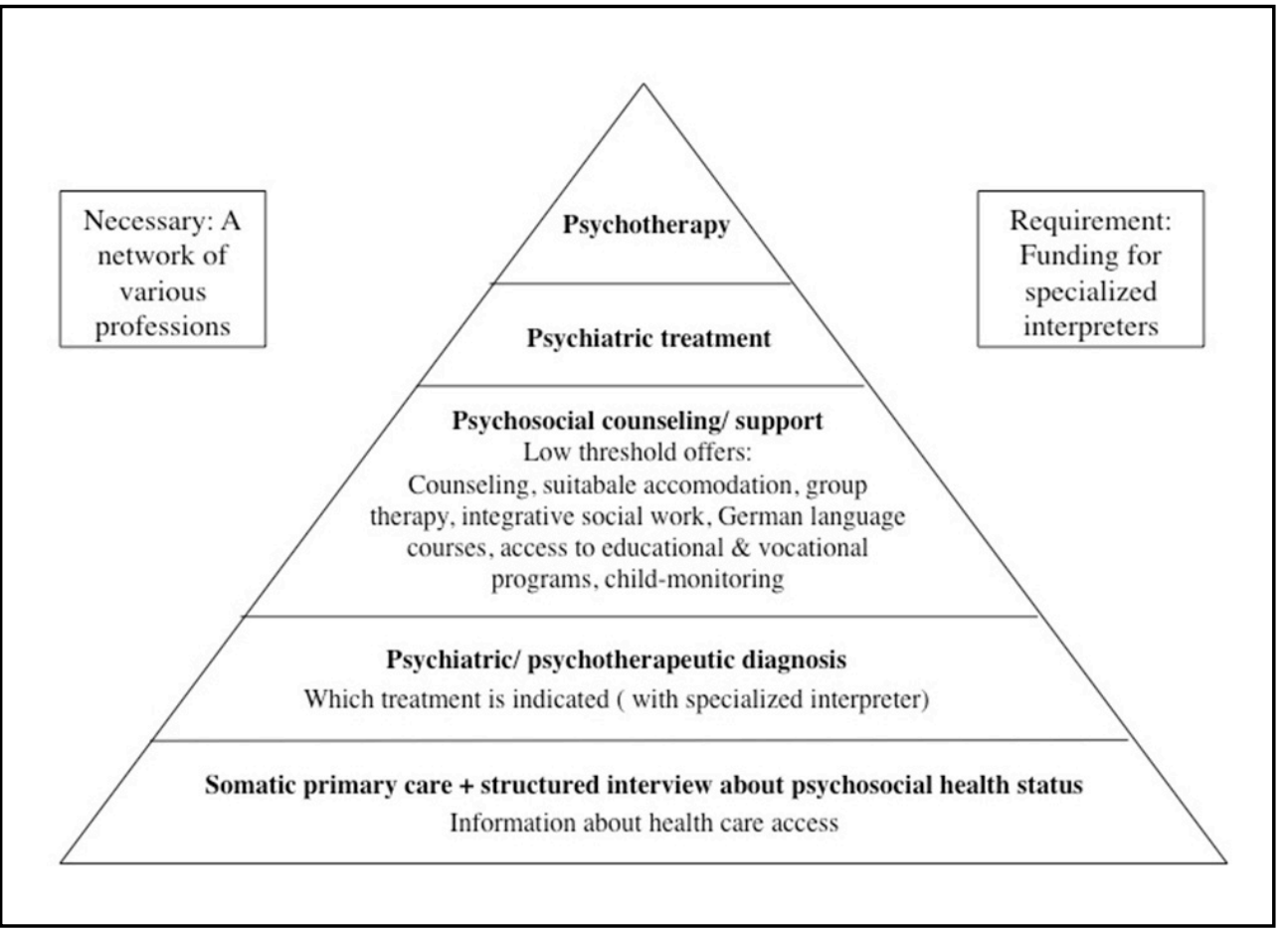

Source: Adapted from Inter-Agency Standing Committee (2007).

psychotherapists. Nonetheless, where no specialized center is accessible, establishing networks of different professions can provide similar levels of care.

Usually, multimodal treatment refers to the application of different interventions and multidisciplinary approaches refer to the collaboration of persons with different professional backgrounds. Multimodal and multidisciplinary approaches often go hand in hand, meaning that a multimodal treatment is carried out by a multidisciplinary team and the terms are often used interchangeably. For reasons of brevity, in the following we only use the term "multimodal" when referring to both multimodal and multidisciplinary treatment.
The multimodal approach addresses the broad spectrum of problems refugees present following exposure to torture or warrelated traumatic events, subsequent post-migration stressors, as well as resettlement and acculturation challenges by providing medical, psychotherapeutic and psychosocial assistance, as well as legal support during the asylum procedures. This approach requires knowledge of psycho-traumatology, at various levels (body, mind, social field), cultural awareness, and specialized interpreters (Maier \& Schnyder, 2007; Pabst, Gerigk, Erdag, \& Paulsen, 2013; Sjölund, Kastrup, Montgomery, \& Persson, 2009). The aim of a multimodal approach is to offer the patients an individually tailored 
psychotherapeutic concept by taking into account the individual's syndrome, their limitations in day to day life, their current situational context, their cultural heritage as well as their level of education (Silove, Ventevogel, \& Rees, 2017). Thereby, a close cooperation between the attending physicians, therapists, lawyers and social workers is necessary. Integrated and wellcoordinated social support fostering the patient's autonomy and inclusion into the host society is necessary for treatment and rehabilitation measures to have an effect (Brandmaier \& Ahrndt, 2012; Gissendanner, Callies, Schmid-Ott, \& Behrens, 2013; Wenk-Ansohn, Weber-Nelson, Hoppmann, \& Ahrndt, 2014). This approach not only aims at alleviating symptoms, but also at supporting the rehabilitation process and in order to include the refugees as best as possible in the host society.

\section{Treatment programs at Center ÜBERLEBEN according to individual indication}

The center is a specialized nongovernmental organization for the treatment and rehabilitation for survivors of torture and war-related violence. Treatment follows the aforementioned multimodal approach including culturally sensitive medical, psychiatric, psychotherapeutic and social treatment services. If indicated, supplementary body and creative therapeutic modules are integrated (Wenk-Ansohn et al., 2014). The psychotherapists at the center have a medical or psychological background and are trained as psychotherapists in a cognitive-behavioral, psychodynamic or systemic approach. In addition, they received trauma-therapeutic trainings. Therapy sessions are conducted with the help of professional interpreters who are specially trained for psychotherapeutic settings (i.e. technically and psychologically) and who receive regular supervision with regard to complex and problematic cases, potential secondary traumatization as well as setting, methods and cultural issues. Depending on the indication presented by the patient, treatment in the center is offered in various settings, such as the outpatient clinic for adults, the outpatient clinic for children and youth, a day clinic and a specialized service for traumatized women. In order to meet the higher influx of refugees to Germany from 2013 onwards and to offer specialized care to persons with an immediate and high need of care and treatment, the outpatient clinic for adults developed an acute treatment program for newly arrived traumatized refugees. It was hypothesized that the early access to adequate care can reduce the symptom severity and also the risk of chronification of trauma-related disorders. The acute program focuses on stabilizing and supporting patients in the particularly vulnerable period after their arrival with a short-term multimodal approach of up to six months as outlined below. For refugees who already lived in a more stable context (e.g. secure residence status, living conditions), but who suffered from complex and mostly chronic posttraumatic symptoms, the outpatient clinic continued to offer a long-term multimodal treatment and rehabilitation program. The longterm program focuses on traumaoriented psychotherapy in combination with integrated clinical social support and lasts on average 1.5 years (WenkAnsohn et al., 2014). A recent evaluation demonstrated that the long-term program was accompanied by a significant decrease in trauma-related psychological symptoms and an increase in subjective quality of life (Stammel et al., 2017). After-care is available for patients after discharge from either program. 
First consultation and acute short-term treatment program

Treatment-seeking refugees are mostly referred to the center through their refugee shelters, through hospitals or through lawyers or they learnt about the center and its services through their community. Refugees who are interested to enter a therapy program at Center ÜBERLEBEN can arrange appointments for a personal interview in a weekly telephone consultation hour. During the telephone consultation, a first screening takes place to assess whether the treatment-seeking person is likely to fulfil the eligibility criteria at Center ÜBERLEBEN (victims of war and/ or torture, trauma-related psychological problems, need for treatment with interpreters). If the person is likely to fulfil these eligibility criteria, and if there is capacity for intake, an extensive initial clinical interview is offered (see Table 1). This interview is conducted with a psychotherapist, a social worker and a specialized interpreter. It covers the client's symptoms, overview of the personal history, needs (psychosocial, psychiatric and psychotherapeutic), and her/his motivation to take part in therapy. At the end of this initial interview, it is determined whether there is an indication for further diagnostics and treatment in the center and which of the support programs will be offered. In case of non-admission to the treatment services, a referral to the public healthcare system or the network of NGOs for psychosocial and legal support is offered. Usually the therapy requests exceed the center's capacities by far, so that only persons who are severely affected will be admitted to the programs.

Inclusion criteria for the acute multimodal treatment program requires patients to be newly arrived in Germany (weeks or a few months), to show acute trauma- and stress-related symptomatology and to have a current unstable context with regard to the asylum procedure and/or living conditions. Most of the patients admitted to

Table 1: Steps before, during and after the initial interview with a specialized interpreter

\author{
Before interview Telephone consultation to register, clarify symptoms, and if appropriate refer to \\ other external offers. \\ During interview Current Symptoms. \\ Biographical background and potentially traumatic experiences (overview). \\ Current stressors. \\ Social situation and asylum status, lawyer. \\ Motivation for treatment. \\ Prior diagnostics and treatment.
}
At the end of Preliminary diagnoses; in cases of no diagnoses, consultation on whether other interview problems present, e.g. main emphasis on current unstable life situation or other external factors.
Motivation for therapy.
Indication for treatment.

Decision
Which measures/treatments are indicated? Which measures can be offered, which cannot? (where applicable: concluding counselling and referral).
Decision whether acute intervention or a long-term psychotherapeutic treatment process is indicated.
If admitted to the acute program treatment, it starts as soon as possible after the initial interview.


Table 2: Elements and steps in the acute short-term program

In case of admission to the acute treatment program:

1. Clinical diagnostic phase-if applicable: documentation of somatic injuries, and if needed preparation of a professional psychotherapeutic statement for the asylum process.

1. Psychological standardized assessment (T1).

2. Up to 25 individual therapy sessions (psychiatric, psychotherapeutic, social therapy).

3. If indicated, in addition - up to 12 group therapy sessions (psychoeducation and body therapy).

4. Along the therapeutic process, integrated autonomy promoting social work.

5. If children accompanied patients, initiation of appropriate help for the children (childmonitoring).

6. Psychological standardized assessment at the end of the program (T2).

7. If necessary: after-care.

$>$ the modules are applied in a flexible manner according to the individual's needs.

the acute program at intake lived in masshousings or provisory shelters.

Table 2 provides an overview of the elements applied within the acute multimodal short-term treatment program. The case example further exemplifies the first consultation.

\section{Reflections by the therapeutic team}

Practical experience with the acute program was gathered in team workshops in order to adjust our procedures to the challenge of delivering a type of service that was new to us. We observed that newly arrived asylum seekers had a higher need for legal counseling provided by social workers compared to patients in the long-term therapy program. In the early stages of the acute program, patients commonly required support with their asylum application, accommodation and with restoring contact with lost relatives. Later, help was needed to access language courses, vocational preparation courses, or job opportunities in general. After a successful asylum application, support might have been needed during the family reunification process. Also, more psychiatric differential diagnostics (e.g. to exclude psychosis, dissociative states, suicidal ideation) and treatment with an anti-depressive medication with sleep-inducing properties was prescribed in many cases, although taken largely only temporarily in the first moths after intake. In many cases, crisis interventions were needed in situations of overwhelming current stressors, such as a negative decision concerning the asylum application, or confrontations with trauma-associated triggers in the accommodation. Likewise, news about renewed conflict at home, where family members might be in danger, often caused major crises. In some patients, these experiences triggered suicidal tendencies and a temporary admission to a psychiatric hospital became necessary.

Though patients benefitted from group therapy, they also reported that individual psychotherapy sessions were of central importance to them. Individual sessions focused on stabilizing and resource-oriented interventions as well as grief counselling. Furthermore, a narrative approach formed an integral part of the acute program (testimonial therapy; Agger, Raghuvanshi, Shabana, Polatin, \& Laursen, 2009), which aimed at reconstructing the biography including traumatic experiences. In many cases, the life line method (manualized by Schauer, Neuner, and Elbert (2011)) was used to identify traumatic as well as positive life events without going into in-depth 


\section{Case example and reflections by the therapeutic team}

Case study (part I)

Mr. A. arrives for a first consultation at the Berlin Center ÜBERLEBEN. He reports that he is 32 years old and arrived from Syria two months ago. Currently he suffers from sleep disturbances such as trouble falling and staying asleep. He describes nightmares, where scenes of torture and bombing occur, with accompanied feelings of fear and arousal. He reports that, in his dreams, he also sees his wife and son yelling for help in their bombedout home, a scene he had not directly witnessed. He reports being restless and irritable, whilst experiencing hopelessness and feelings of increasing tiredness, guilt and uselessness in combination with worries that he might not be able to bring his family to Germany. He reports that he had taken the overland route and had been arrested, beaten and registered by the Bulgarian border police. Now he faces the threat of deportation to Bulgaria due to the 'Dublin procedure'. $\mathrm{He}$ describes the living conditions for a refugee family in Bulgaria as being inhumane. He mentions that he feels trapped and that sometimes he had even considered ending his own life. When asked about difficult experiences in Syria, he discloses that he had been imprisoned in Damascus for two years and that a number of his political friends had died during incarceration and that he also has scars from torture. During the first consultation he does not want to go into further details about his experiences during his imprisonment. $\mathrm{He}$ reports that his family paid money to get him released from prison. Also, that he witnessed bombings and that he transported injured persons with his van. When asked about the course of his symptoms, Mr. A. mentions having nightmares since release from prison, albeit more severe since arriving in Europe and that he feels hopeless and without energy (he begins to cry). He's currently living in a refugee shelter and feels ashamed because he screams in his dreams. Due to his acute symptomatology and his ongoing unsafe and stressful situation, he is admitted to the acute program where support will start immediately. exposure. The life-line method focuses on bringing life experiences into a coherent narrative and providing some cognitive restructuring inputs or interventions concerning psychodynamic aspects. Patients evaluated the possibility of communicating their experience to an empathic and neutral listener, who set a framework and limited the amount of the exposure to a bearable limit, as helpful and relieving. By working with the narrative approach, the traumatic experience is disclosed as far as possible in the actual psychological status, allowing the therapist in later stages of the therapeutic process to expand on it when working with individual triggers, on contents of nightmares, and feelings of powerlessness, shame and guilt (Boos, 2005).

We were able to discharge most of the participating patients within the six-month 
period of the acute program, whereas only a minority of the patients indicated a need and motivation to continue therapy in the scope of the trauma-oriented long-term therapy program. The majority reported that after having received intensive support in the early stage after flight from the acute program, they then felt sufficiently stabilized to manage their daily life in exile. They had become more active and started to visit language or professionalizing courses. Many of those who had gone through the acute program, especially those who were still waiting to hear about their asylum claim, or ongoing worries about their family in their country of origin made use of low frequency appointments or crisis interventions on demand within our after-care offer.

Working with newly-arrived, severely traumatized refugees was highly demanding for the team of the outpatient clinic. The therapists and interpreters had insights into the atrocities the patients had gone through. The team was often confronted with critical states, dissociative fits and suicidal tendencies of their patients. To reduce the strain of the team and prevent compassion fatigue (Figley, 1995), multidisciplinary case conferences and external supervisions of all persons involved in the care setting was necessary. Also, the option to debrief after a particularly straining session was important for the team members working in the acute program. Without the option to share and discuss as well as supporting each other, therapists and interpreters were at a high risk of burnout, whereas sharing and also communicating successes helped to alleviate the strain and brought energy and job satisfaction.

\section{Method}

The purpose of the present study was to evaluate the progress of patients participating in the short-term multimodal acute treatment program by examining changes in PTSD, anxiety and depression symptom severity in the course of treatment. We hypothesized that patients even in this early phase of their asylum process and under conditions of ongoing post-migration stressors can benefit from a multimodal treatment approach by showing a decrease in PTSD, anxiety and depressive symptoms, thus enabling them to better manage their life in exile.

During the diagnostic phase at the beginning of the acute program, a psychological standardized assessment was carried out assessing exposure to traumatic events and symptom severity of PTSD, depression and anxiety (T1). Exclusion criteria for the standardized assessment were acute suicidality, severe dissociative disorder or psychotic symptomatology. Following completion of the acute program after approximately six months ( $M=201$ days; $\mathrm{SD}=83$ ), a second standardized assessment was carried out (T2).

The data included in the present study were collected between February 2015 and May 2017. During that period, 1,484 persons made use of the telephone consultation seeking advice or a place for treatment. Based on this consultation, an initial interview for 359 people was carried out at the outpatient clinic for adults, thereafter 169 persons were assigned to the short-term acute treatment approach as they fulfilled the inclusion criteria. Moreover, 190 persons were either assigned to the long-term treatment approach of the center or referred to other internal or external offers. Of the 169 persons assigned to the short-term acute treatment approach, 92 persons completed the standardized mental health assessment by filling in the questionnaires. 77 persons were excluded from the standardized assessment due to fulfilling one the exclusion criteria (see above). In most cases, the questionnaires (i.e. 
Case study (part II)

Upon admittance, Mr. A. showed symptoms related to PTSD after a series of sequential traumatic experiences while simultaneously suffering from a depressive syndrome as a result of the current ongoing stressful situation. Due to his depressive symptoms and in order to alleviate his sleep problems, he was prescribed an anti-depressive medication (Mirtazapine 30mg), which he took for only three months. The social worker organized Mr A.'s participation in a German language course and recommended a lawyer for the asylum process. Subsequently, Mr. A. was willing to talk about his experiences during his imprisonment. Scars from injuries where documented according to the Istanbul Protocol (United Nations High Commissioner for Refugees, 2001) and a comprehensive professional statement was prepared. Additionally, the patient took part in a psychoeducative group. A major topic in the individual psychotherapeutic sessions was his feeling of guilt towards his family, whom he had to leave behind during his flight, and towards the fellow inmates in prison, some of whom died during incarceration.

The Federal Office for Immigration and Refugees (BAMF) decided not to activate the Dublin procedure and processed his request for asylum in Germany. He was granted asylum according to the Geneva Refugee Convention, which relieved him immensely, especially since he was now able to request a family reunification with the support of the social worker.
Overall, at the end of the acute program, the depressive and PTSDsymptoms had significantly decreased, the PTSD symptoms still being above the cut-off point. Mr. A. did not accept the offer to continue his treatment in terms of a long-term trauma-oriented psychotherapy. He was at the point of prioritizing his practical life in Germany. He provided the feedback that the program had helped him immensely, and that he also learned that therapeutic conversations worked. He asked if he could report back to us if the symptoms persisted or became worse. To support his desire to start working as soon as possible, the social worker was able to organize a vocational preparation course.

Mr. A. returned twice in the frame of aftercare requiring assistance in managing crisis situations. The family reunification request took time and during both crises bombing in Syria caused the telephone connection to disconnect. Both times, Mr. A. despaired and even considered going back to Syria. After approximately six months, he arrived at the center without an appointment. He was radiant with joy and had his wife and two kids (a girl, 10 years of age, and a boy, 5 years of age) with him. We had a small celebration together. However, his wife reported that her daughter often screamed in her sleep and was overly introvert. Thus, we organized a first consultation with an Arabic speaking children and adolescent psychiatrist for diagnostic and parental counselling (child monitoring makes part of the program). 
$\mathrm{T} 1$ and T2) were carried out via face-to-face interviews with clinical psychologists and interpreters while some patients filled out the questionnaires in their own homes by themselves. Informed consent was obtained from every participant at $\mathrm{T} 1$.

\section{Instruments}

Sociodemographic information included gender, age and country of origin. The number of either psychotherapy, social work, group therapy and psychiatric treatment sessions the patient had received was noted according to our digital patient documentation. These included questionnaires (described below) which were translated into Arabic, Farsi, Turkish and Russian and then back-translated by an interpreter unfamiliar with the original version. Discrepancies between translation and back-translation were discussed until a final version was agreed upon following a rigorous translation process as recommended for cross-cultural research (Guillemin, Bombardier, \& Beaton, 1993).

Traumatic Events: Traumatic events were assessed using an adjusted list based on two standardized instruments, the Harvard Trauma Questionnaire (Mollica et al., 1992) and the Posttraumatic Diagnostic Scale (Foa, Cashman, Jaycox, \& Perry, 1997). Therefore, 24 traumatic events were assessed altogether, including one item allowing participants to indicate an additional traumatic event. Participants were asked whether they had personally experienced, witnessed, or heard/learnt of the event.

PTSD: The Posttraumatic Stress Disorder Checklist for DSM-5 (PCL-5) is a screening instrument for PTSD including 20 items that correspond to the diagnostic criteria of PTSD of the DSM-5 (Blevins, Weathers,
Davis, Witte, \& Domino, 2015). Items are rated on a five-point Likert scale ranging from 0 "not at all" to 4 "extremely". A preliminary cut-off of 33 suggested to indicate a severity of PTSD symptoms at a clinical level (Weathers et al., 2013). The PCL-5 shows good psychometric properties (Blevins et al., 2015). In the current sample, Cronbach's alpha was .82.

Depression and Anxiety: The Hopkins Symptom Checklist-25 (HSCL-25) is a 25item questionnaire based on self-report data containing two subscales which measure symptoms of anxiety (items $1-10)$ and depression (items 11 - 25) (Derogatis, 1974). It is a well-established screening instrument and has been widely used in a number of different cultural contexts (Ventevogel et al., 2007). Each item is ranked on a fourpoint Likert scale from 1 "not at all" to 4 "extremely"). To interpret the results, the mean value of each of the subscales is calculated and a cut-off value of $>1.75$ is suggested to identify clinically relevant symptomatology. Current evidence supports the construct validity and reliability of the Arabic version of the instrument (Selmo, Koch, Brand, Wagner, \& Knaevelsrud, 2016). Cronbach's alpha in this sample was $a=.85$ for anxiety and $a=.86$ for depression.

\section{Participants}

The total sample at $\mathrm{T} 1$ consisted of $\mathrm{N}=$ 92 participants. Approximately 80 per cent were male $(81.5 \% ; \mathrm{n}=75)$. The sample had a mean age of $\mathrm{M}=31.25$ years, $\mathrm{SD}=9.05$ (range: 18-55). The majority of participants came from Syria $(n=48,52.2 \%), 12.0 \%$ $(\mathrm{n}=11)$ from Afghanistan, $7.6 \%(\mathrm{n}=7)$ from Iraq, and $7.6 \%(n=7)$ from Turkey, others came from Iran, Iraq, Pakistan, Egypt, Chechnya, Somalia, Eritrea, Libya or Lebanon (Palestinians). 
Data for exposure to traumatic events were available for only 77 participants. The most frequently reported personally experienced traumatic events were "being close to death" ( $\mathrm{n}=68,87.2 \%)$, "exposure to combat situation" $(78.9 \%, \mathrm{n}=60)$ and "assault by a stranger" $(76.9 \%, \mathrm{n}=60)$. Torture (as defined by UNCAT) was reported by $70.1 \%(n=54)$ on the traumatic events list. Of the 92 patients who completed T1, 44 completed T2 assessments.

\section{Statistical Analyses}

Missing data were analyzed for systematic patterns. Missing data in the pre-post comparison $(n=44)$ were missing completely at random (MCAR) and were replaced separately for pre and post data using Estimation Maximation methods (Tabachnick \& Fidell, 2001). T-tests and the chi-square test were applied to test whether completers and non-completers differed in terms of sociodemographic variables or symptom severity of PTSD, depression, and anxiety. For pre-post comparison, completer analyses were conducted. Paired sample t-tests were individually performed for PTSD and each of the PTSD symptom clusters, anxiety, and depression. Cohen's d was calculated as a measure for the respective effect sizes $(\mathrm{d}=$ .20: small effect, $\mathrm{d}=.50$ : medium effect, $\mathrm{d}=$ .80: large effect, according to Cohen (1988)). All statistical analyses were conducted using SPSS, version 24 .

\section{Results}

Severity of symptoms at $T 1 \quad(N=92)$

Of the entire sample $(\mathrm{N}=92), 95.7 \%$ ( $=88$ ) fulfilled the criteria for PTSD as measured with the PCL-5 with a mean severity of symptoms of $\mathrm{M}=54.25$ ( $\mathrm{SD}=$ 11.79). Similarly, $95.7 \%(n=88)$ scored above the cut-off of 1.75 for depression on the HSCL-25 with a mean symptom severity of $3.03(\mathrm{SD}=0.62)$. Finally, $93.5 \%(\mathrm{n}=$ 86) of the patients scored above the cut-off for anxiety with a mean symptom severity of $2.92(\mathrm{SD}=0.71)$.

Patients with pre-post test diagnostics $(n=44)$ For pre-post comparisons, data were available for $\mathrm{n}=44$ participants $(\mathrm{n}=35(79.5 \%)$ male; age $M=30.64, S D=9.46)$. In total, 48 participants did not fill out the post assessment (T2) due to several reasons: several patients were released from treatment earlier than three months after T1 or dropped out of treatment, one patient was deported to Spain under the Dublin procedure; some were discharged after six months without a final assessment after having missed the appointment for the final testdiagnostic assessment repeatedly, seven patients with ongoing difficulties in managing a day-to-day structure were referred to intensive daily care at the day clinic or the women's housing program of the center and about $20 \%$ of patients initially admitted for the acute program were transferred to the longterm treatment program. However, completers and non-completers did not differ from each other in any of the sociodemographic variables age $(\mathrm{t}(90)=0.62, \mathrm{p}=.54)$ or gender $\left(\chi^{2}=\right.$ $.22, \mathrm{p}=.64)$, nor the severity of symptoms of PTSD $(\mathrm{t}(90)=0.16, \mathrm{p}=.87)$, depression $(\mathrm{t}(90)=-0.79, \mathrm{p}=.43)$ and anxiety $(\mathrm{t}(90)=$ $-0.26, \mathrm{p}=.80)$ at the initial assessment $(\mathrm{T} 1)$.

At the beginning of treatment (T1), four of the 44 participants $(9.1 \%)$ had been granted asylum, while $31(70.5 \%)$ were still in the asylum process. The remaining nine patients had either been denied asylum $(n=1)$, were temporarily protected from deportation $(n=1)$, or were undergoing the Dublin regulation $(n=7)$.

At T2, 13 (29.5\%) had been granted asylum and $23(52.3 \%)$ were still in the asylum process. From the remaining patients, six (13.6\%) where temporarily 
protected from deportation, and two (4.5\%) still faced the Dublin regulation.

All patients received psychotherapy and at $\mathrm{T} 2$, patients had received an average of 14 individual sessions of psychotherapy $(M=13.68, S D=8.22) .63 .4 \%(n=28)$ also received psychiatric sessions (about 4 sessions on average $(\mathrm{M}=3.86, \mathrm{SD}=$ 3.45) but not all of those were treated with a medication. The majority of patients received social work $(\mathrm{n}=38,86.4 \%)$ and had an average of four sessions of social work $(M=4.48, S D=2.84)$. About half of the patients had participated in group therapy $(n=24,54.5 \%)$ and received on average six sessions of group therapy (including psychoeducation and body work; $\mathrm{M}=5.58, \mathrm{SD}=3.48$ ).

Pre-Post comparison $(n=44)$

Table 3 presents pre- and post-comparison data and results of the dependent t-test for all symptom clusters. Results indicate a significant decrease in symptom severity for depression, anxiety, and overall PTSD. While the PTSD symptom clusters 'intrusion', 'changes in mood,' and 'cognition,' and 'alterations in arousal and reactivity' show a significant decrease in severity, the cluster 'avoidance' increased slightly, however to a non-significant degree. Effect sizes for reductions of depressive and overall PTSD symptomatology, PTSD intrusions, PTSD alterations in arousal and reactivity can be classified as large, whereas the effect size for the reduction of anxiety symptoms and PTSD changes in mood and cognition can be classified as medium according to the conventions of Cohen (1988).

While at the beginning of treatment (T1), 97.7\% ( $\mathrm{n}=43)$ fulfilled diagnostic criteria for each PTSD and depression, and $95.5 \%(n=42)$ for anxiety, at $\mathrm{T} 2$, $70.5 \%(\mathrm{n}=31)$ still fulfilled the criteria for clinically relevant PTSD, $79.5 \%(n=35)$ for depression and $70.5 \%(n=31)$ for anxiety.

Table 3: Means and standard deviation for pre and post data $(n=44)$

\begin{tabular}{llllll}
\hline & $\mathrm{T} 1$ & $\mathrm{~T} 2$ & $\mathrm{~T}(\mathrm{df})$ & $p$ & Cohen's d [95\% CI] \\
& $\mathrm{M}(\mathrm{SD})$ & $\mathrm{M}(\mathrm{SD})$ & & & \\
\hline PTSD & $54.04(11.65)$ & $42.19(15.20)$ & $5.32(43)$ & $<.001$ & $0.88[0.26-1.49]$ \\
$\quad$ & $15.39(3.44)$ & $11.50(4.71)$ & $5.08(43)$ & $<.001$ & $0.94[0.32-1.57]$ \\
$\begin{array}{l}\text { Intrusion } \\
\text { Avoidance }\end{array}$ & $4.71(2.65)$ & $5.55(2.32)$ & $-1.66(43)$ & .10 & \\
$\begin{array}{l}\text { Changes in } \\
\text { mood and } \\
\text { cognition }\end{array}$ & $18.11(5.59)$ & $14.10(6.09)$ & $3.98(43)$ & $<.001$ & $0.69[0.08-1.29]$ \\
$\begin{array}{l}\text { Alterations in } \\
\text { arousal and } \\
\text { reactivity }\end{array}$ & $15.83(4.14)$ & $11.04(6.00)$ & $5.75(43)$ & $<.001$ & $0.93[0.31-1.55]$ \\
$\begin{array}{l}\text { Anxiety } \\
\begin{array}{l}\text { Depression } \\
\hline\end{array}\end{array}$ & & & & & \\
\hline
\end{tabular}

Note: abbreviations: $\mathrm{df}=$ degrees of freedom $\mathrm{CI}=$ Confidence Interval, $\mathrm{M}=$ mean, $\mathrm{SD}=$ standard deviation, $\mathrm{T}=\mathrm{t}$-test, $\mathrm{p}=$ significance level 


\section{Discussion}

The aim of the study was to evaluate the short-term multimodal acute treatment at the outpatient clinic at Center ÜBERLEBEN. The results show a significant decrease in symptomatology between pre- and post-treatment measurement for overall PTSD, anxiety, and depression. Despite the extremely high symptom load at the beginning of treatment, the uncertainties regarding residence status, and the often ongoing difficult living conditions in refugee accommodation, patients seem to benefit from the multimodal short-term treatment. Large effect sizes were found with regard to reductions in overall PTSD and depression and a medium effect size was found for reductions in anxiety symptoms. This adds to previously inconsistent findings on the efficacy of multimodal treatment which in some cases has not found any changes in PTSD, depression and anxiety between pre- and post-treatment assessments (Birck, 2004; Carlsson, Mortensen, \& Kastrup, 2005; Mollica et al., 1990), while other studies have found significant reductions in symptom severity (Arcel et al., 2003; Brune, Eiroa-Orosa, Fischer-Ortman, \& Haasen, 2014; Palic \& Elklit, 2009; Stammel et al., 2017). However, assessments at T2 showed that after treatment, about $70 \%$ of the patients still scored above the cut-off for PTSD and anxiety and about $80 \%$ for depression. Previous research shows that refugees often still suffer from high rates of psychopathology, after treatment (de Heus et al., 2017; Schock, Böttche, Rosner, Wenk-Ansohn, \& Knaevelsrud, 2016; Stammel et al., 2017). There are several reasons why refugees may benefit less from psychotherapy compared to non-refugee patients. First, with respect to this study, only severely affected cases with an urgent need for treatment were admitted to the treatment, so that patients had on average very high symptom loads at the beginning of treatment. An earlier meta-analysis has shown that high pre-treatment PTSD severity was predictive of smaller treatment effects than moderate symptom severity at intake (Haagen, Smid, Knipscheer, $\&$ Kleber, 2015). Second, refugees are confronted with a wide range of ongoing stressors. After discharge from our acute program, more than half of our patients were still waiting for an asylum decision or for family reunification, and most of the patients were still living in refugee accommodation. These factors may have substantially contributed to an increased symptom severity (Nickerson, Steel, Bryant, Brooks, \& Silove, 2011; Schock et al., 2016).

The long-term course of the wellbeing of traumatized refugees not only depends on successful therapeutic and psychosocial interventions but to a large part on the safety, living-conditions and social openness of the country of exile. Therefore, part of our acute program was to document their history and write expert opinions for the asylum procedure. Patients who still suffered from reactive psychological symptoms at or following the end of the acute program, could attend the aftercare program of the outpatient clinic that offered further support with low frequency sessions or crisis interventions, when necessary.

Results further showed that while symptom severity in the PTSD symptom clusters 'intrusions', 'changes in mood and cognition', and 'alterations in arousal and reactivity' significantly decreased, the mean symptom severity in 'avoidance' did not change. This finding may be explained by the fact that the acute short-term treatment program, primarily focused on supporting patients to manage current stressors, 
symptoms, and trauma-associated triggers, an approach that may not be sufficiently effective to treat avoidant behavior in PTSD. In personal feedback, some patients revealed that when responding to the questionnaire they had indicated avoidance because they had improved their ability to control trauma-related triggers consciously. For example, they would not watch news about war-related developments in their home country late at night anymore, which in turn had resulted in better sleep and a reduction in nightmares. A traumafocused approach, that in various studies was demonstrated to be an efficacious approach to treating PTSD in war-exposed refugee populations (see meta-analysis by Lambert \& Alhassoon, 2015), was not the primary focus of this program. The reason behind not primarily conducting a traumafocused approach was that not only war- or flight-related trauma were the cause for the patients' symptomatology, but also postmigration stressors such as uncertainty regarding residence status in the host country and worries about family members who were still exposed to war in their home countries (Miller \& Rasmussen, 2010), or even wounded, killed or missing. An indepth processing of traumatic memories during the phase of acute stressors was not indicated in this early period of migration since the traumatic process the patients were in was still ongoing (Flatten et al., 2011). Although the acute program only allowed a mild trauma-focused approach, pre to post treatment assessment indicated a significant reduction of symptoms including PTSD even after the relatively short treatment period of six months.

\section{Limitations of the study}

Several limitations of the study should be considered when interpreting the results.
First, this study was conducted without a control group. It is therefore not possible to state whether the effects found can be attributed to the intervention itself or rather to spontaneous remission of symptoms, or to the effects of attention received by the patients within the therapeutic relation. However, due to the ongoing stressors and uncertainties regarding residence and housing situation, substantial changes in the symptom load without therapeutic interventions cannot be expected. As many patients were male family fathers whose families were still in the conflict-affected regions, having a regular appointment with a supportive listener may have been particularly effective in dealing with feelings of guilt, hopelessness and loneliness. Although it would be advisable for future research to use control groups to measure the efficacy of multimodal interventions as compared to a waiting list, it has to be noted that for ethical reasons, it is difficult to have a waiting list for a period of six months when offering therapeutic support for traumatized persons in an acutely stressful situation.

Second, for a variety of reasons, about half of the patients assessed at T1 did not participate in the second assessment. Thus, we cannot rule out the possibility that a selection bias occurred in the sense that only those patients who benefitted from therapy were assessed at the second time point. However, patients did not differ from each other with regard to sociodemographic data or symptom severity at $\mathrm{T} 1$, so that a systematic reason for the dropout from the second assessment could not be identified in this regard. Furthermore, we performed a completer-analysis, which generally shows larger effects than intention-to treat analysis and is therefore at risk of overestimating the treatment effect. 
Third, the interventions applied were not standardized but therapeutic modules were applied in a flexible way. Thus, the evaluation at hand does not allow conclusions about effective components responsible for improvements in symptomatology. The current analysis was conducted in a natural setting with the primary objective to provide multimodal treatment tailored to the needs of these patients. The scientific objective was only secondary and the data should therefore be seen as preliminary and explorative.

Fourth, we used different language versions of each questionnaire, which might result in a bias in responsiveness. However, we used the recommended procedure for translating questionnaires to ensure a rigorous translation process.

\section{Conclusions}

This study evaluated an acute short-term multimodal treatment program for newlyarrived traumatized asylum seekers and provided reflections on the experiences within this program. Our results suggest that the early access to this type of treatment seems to result in significant decreases in trauma-related symptoms. So far, the results of the acute program have been promising: On admission, all patients who took part in the survey were severely strained and more than $95 \%$ of patients were suffering from severe symptoms of PTSD, anxiety and depression. Results show that within the six-month period of the acute program, it seems possible to stabilize the majority of patients. However, we do not yet know if the reduction of symptom levels is stable over time and if the program helped patients in their participation in the host society. We assume that some participants of the acute treatment program will later on sign up for further trauma-oriented psychotherapy due to remaining or recurrent symptoms. Despite methodological shortcomings, this study adds further preliminary evidence to the efficacy of multimodal treatment and shows that improvements in symptom severity can be achieved even within the vulnerable period after arrival in the host country.

\section{Acknowledgements}

We would like to thank Benedikt Taud for the translations and Maike Stolz for the preliminary analyses. We would like to express our gratitude towards the specialized interpreters at our center for their support in collecting the data. Furthermore, we thank our patients who agreed to take part in this study.

\section{References}

Agger, I., Raghuvanshi, L., Shabana, S., Polatin, P., \& Laursen, L. K. (2009). Testimonial therapy. A pilot project to improve psychological wellbeing among survivors of torture in India. Torture 19(3), 204-217.

Arcel, L. T., Popovic, S., Kucukalic, A., BravoMehmedbasic, A., Ljubotina, D., Pušina, J., \& Šaraba, L. (2003). The Impact of Short-term Treatment on Torture Survivors. The Change in PTSD, Other Psychological Symptoms and Coping Mechanisms after Treatment. In: Treatment of torture and trauma survivors in a post-war society. Association for Rehabilitation Torture Victims; Center for Torture Victims, Sarajevo.

Birck, A. (2004). Symptomatik bei kriegs-und folterüberlebenden Flüchtlingen, mit und ohne Psychotherapie. Zeitschrift für Klinische Psychologie und Psychotherapie; Forschung und Praxis, 33(2), 101-109. http://doi.org/10.1026/00845345.33.2.101

Blevins, C. A., Weathers, F. W., Davis, M. T., Witte, T. K., \& Domino, J. L. (2015). The posttraumatic stress disorder checklist for DSM-5 (PCL-5): Development and initial psychometric evaluation. Fournal of Traumatic Stress, 28(6), 489-498. http:// doi.org/10.1002/jts.22059

Bogic, M., Njoku, A., \& Priebe, S. (2015). Longterm mental health of war-refugees: a systematic literature review. BMC International Health and Human Rights, 15(1), 29. http://doi.org/10.1186/ s12914-015-0064-9 
Boos, A. (2005). Kognitive Verhaltenstherapie nach chronischer Traumatisierung: Ein Therapiemanual. Göttingen: Hogrefe Verlag.

Bozorgmehr, K., \& Razum, O. (2015). Effect of Restricting Access to Health Care on Health Expenditures among Asylum-Seekers and Refugees: A Quasi-Experimental Study in Germany, 1994-2013. PloS One, 10(7), e0131483. http://doi.org/10.1371/journal.pone.0131483

Brandmaier, M., \& Ahrndt, A. (2012). Neue Perspektiven-Klinische Sozialarbeit mit traumatisierten Flüchtlingen [New PerspectivesClinical social work with traumatized refugees.] In S. Gahleitner \& G. Hahn (Eds.), Übergänge gestalten, Lebenskrisen begleiten (pp. 305-323). Bonn: Psychiatrie Verlag.

Brewin, C. R., Cloitre, M., Hyland, P., Shevlin, M., Maercker, A., Bryant, R. A., . . . Reed, G. M. (2017). A review of current evidence regarding the ICD-11 proposals for diagnosing PTSD and complex PTSD. Clinical Psychology Review, 58(Supplement C), 1-15. http://doi.org/10.1016/j. cpr.2017.09.001

Brune, M., Eiroa-Orosa, F. J., Fischer-Ortman, J., \& Haasen, C. (2014). Effectiveness of psychotherapy for traumatized refugees without a secure residency status. International fournal of Migration, Health and Social Care, 10(1), 52-59. http://doi.org/10.1108/IJMHSC-07-2013-0022

Bundesamt für Migration und Flüchtlinge [German Federal Agency of Migration and Refugees]. (2017). Das Bundesamt in Zahlen 2016. Asyl [The Federal Office in figures 2016. Asylum]. https://www.bamf.de/SharedDocs/Anlagen/ DE/Publikationen/Broschueren/bundesamt-inzahlen-2016.pdf?_blob=publicationFile

Bundesweite Arbeitsgemeinschaft der psychosozialen Zentren für Flüchtlinge und Folteropfer (BafF e.V) [German Network of Rehabilitation Centres for Refugees and Survivors of Torture]. (2016). Versorgungsbericht zur psychosozialen Versorgung von Flüchtlingen und Folteropfern in Deutschland (3. Auflage) [Report on the Psychosocial Care of Refugees and Torture Victims in Germany]. http://www. baff-zentren.org/wp-content/uploads/2017/02/ Versorgungsbericht_3-Auflage_BAfF.pdf

Butollo, W., \& Maragkos, M. (2012). Gutachterstelle zur Erkennung psychischer Störungen bei Asylbewerbern [Auditor for the detection of mental disorders in asylum seekers.] http:// www.pgasyl.de/cms/images/stories/PGAsyl/ abschlussbericht $\% 201 \mathrm{mu} \% 20$ endfassung $\% 20$ 17.12.2012.pdf

Carlsson, J. M., Mortensen, E. L., \& Kastrup, M. (2005). A Follow-Up Study of Mental
Health and Health-Related Quality of Life in Tortured Refugees in Multidisciplinary Treatment. Fournal of Nervous and Mental Disease, 193(10), 651-657. http://doi.org/10.1097/01. nmd.0000180739.79884.10

Chung, M. C., Shakra, M., AlQarni, N., AlMazrouei, M., Al Mazrouei, S., \& Al Hashimi, S. (2018). Posttraumatic Stress Among Syrian Refugees: Trauma Exposure Characteristics, Trauma Centrality, and Emotional Suppression. Psychiatry, 1-17. http://doi.org/10.1080/0033274 7.2017.1354620

CIR Rifugiati. (2017). Time for needs: Listening, healing, protecting. https://www.ueberleben.org/wpcontent/uploads/2017/10/Report_TIME-FORNEEDS_CIR.pdf

Cohen, J. (1988). Statistical power analysis for the behavioral sciences (2nd ed.). New York: Academic Press.

de Heus, A., Hengst, S. M. C., de la Rie, S. M., Djelantik, A. A. A. M. J., Boelen, P. A., \& Smid, G. E. (2017). Day patient treatment for traumatic grief: Preliminary evaluation of a one-year treatment programme for patients with multiple and traumatic losses. European fournal of Psychotraumatology, 8(1). http://doi.org/10.1080/2 0008198.2017 .1375335

European Union. (2013). Directive 2013/33/EU of the European Parliament and the Council of 26 Fune 2013. Brussels: Official Journal of the European Union, 29.6.2013 (L 180/96)

Fazel, M., Wheeler, J., \& Danesh, J. (2005). Prevalence of serious mental disorder in 7000 refugees resettled in western countries: a systematic review. The Lancet, 365(9467), 1309-1314. http://doi. org/10.1016/S0140-6736(05)61027-6

Figley, C. R. (1995). Compassion fatigue: Toward a new understanding of the costs of caring. In Secondary traumatic stress: Self-care issues for clinicians, researchers, and educators. (pp. 3-28). Baltimore, MD, US: The Sidran Press.

Flatten, G., Gast, U., Hofmann, A., Knaevelsrud, C., Lampe, A., Liebermann, P., Maercker, A., Reddemann, L., Wöllern, W. (2011). S3LEITLINIE Posttraumatische Belastungsstörung ICD-10: F43. 1 [S3-Guidelines Posttraumatic stress disorder ICD-10: F43.1]. Trauma und Gewalt, 5(3), 202-210.

Foa, E. B., Cashman, L., Jaycox, L., \& Perry, K. (1997). The validation of a self-report measure of posttraumatic stress disorder: The Posttraumatic Diagnostic Scale. Psychological Assessment, 9(4), 445-451. http://doi.org/10.1037/10403590.9.4.445

Führer, A., Eichner, F., \& Stang, A. (2016). Morbidity of asylum seekers in a medium-sized 
German city. European fournal of Epidemiology, 1-4. http://doi.org/10.1007/s10654-016-0148-4

Gäbel, U., Ruf, M., Schauer, M., Odenwald, M., \& Neuner, F. (2006). Prävalenz der Posttraumatischen Belastungsstörung (PTSD) und Möglichkeiten der Ermittlung in der Asylverfahrenspraxis [Prevalence of posttraumatic stress disorder (PTSD) and ways of identification in asylum procedures practice]. Zeitschrift für Klinische Psychologie und Psychotherapie, 35(1), 1220. http://doi.org/10.1026/1616-3443.35.1.12

Gissendanner, S., Callies, I., Schmid-Ott, G., \& Behrens, K. (2013). Migrantinnen und Migranten zwischen Trauma und Traumabewältigung. Implikationen aus Migrationssoziologie und interkultureller Psychotherapie für die psychiatrische, psychosomatische und psychotherapeutische Behandlungspraxis [Migrants between trauma and trauma coping. Implications of migration sociology and intercultural psychotherapy for psychiatric, psychosomatic and psychotherapeutic treatment practice]. In R. E. Feldmann \& G. H. Seidler (Eds.), Traum (a) Migration. Aktuelle Konzepte zur Therapie traumatisierter Flüchtlinge und Folteropfer (pp. 61-80). Gießen: Psychosozial-Verlag.

Guillemin, F., Bombardier, C., \& Beaton, D. (1993). Cross-cultural adaptation of health-related quality of life measures: Literature review and proposed guidelines. Fournal of Clinical Epidemiology, 46(12), 1417-1432. http://doi. org/10.1016/0895-4356(93)90142-N

Gurris, N. F., \& Wenk-Ansohn, M. (2013). Folteropfer und Opfer politischer Gewalt [Victims of torture and victims of political violence.] In: A. Maercker (Ed.), Posttraumatische Belastungsstörungen (4th ed., pp. 525-574). Berlin \& Heidelberg: Springer.

Haagen, J. F. G., Smid, G. E., Knipscheer, J. W., \& Kleber, R. J. (2015). The efficacy of recommended treatments for veterans with PTSD: A metaregression analysis. Clinical Psychology Review, 40, 184-194. https://doi. org/10.1016/j.cpr.2015.06.008

Herman, J. L. (1992). Complex PTSD: A syndrome in survivors of prolonged and repeated trauma. Fournal of Traumatic Stress, 5(3), 377-391. doi:10.1002/jts. 2490050305

Inter-Agency Standing Committee. (2007). IASC Guidelines for mental health and psychosocial support in emergency settings.

Lambert, J. E., \& Alhassoon, O. M. (2015). Traumafocused therapy for refugees: Meta-analytic findings. Fournal of Counseling Psychology, 62(1), 28-37. http://doi.org/10.1037/cou0000048
Leisering, B. (2018). Geflüchtete Menschen mit Behinderungen: Handlungsnotwendigkeiten für eine bedarfsgerechte Aufnahme in Deutschland [Refugees with disabilities: Need for action for needs-based admission in Germany]. https://www.institutfuer-menschenrechte.de/fileadmin/user_upload/ Publikationen/POSITION/Position_16_ Gefluechtete_mit_Behinderungen.pdf

Maier, T., \& Schnyder, U. (2007). Psychotherapie mit Folter-und Kriegsopfern: Ein praktisches Handbuch [Psychotherapy with Torture and Victims of War: A Practical Handbook]. Bern: Hans Huber/Hogrefe.

Miller, K. E., \& Rasmussen, A. (2010). War exposure, daily stressors, and mental health in conflict and post-conflict settings: Bridging the divide between trauma-focused and psychosocial frameworks. Social Science and Medicine, 70(1), 7-16. http://doi.org/10.1016/j. socscimed.2009.09.029

Mollica, R. F., Caspiyavin, Y., Bollini, P., Truong, T., Tor, S., \& Lavelle, J. (1992). The Harvard Trauma Questionnaire: Validating a crosscultural instrument for measuring torture, trauma, and posttraumatic-stress disorder in Indochinese refugees. Fournal of Nervous and Mental Disease, 180(2), 111-116. http://doi. org/10.1097/00005053-199202000-00008

Mollica, R. F., Wyshak, G., Lavelle, J., Truong, T., Tor, S., \& Yang, T. (1990). Assessing symptom change in Southeast Asian refugee survivors of mass violence and torture. The American fournal of Psychiatry, 147(1), 83-88. http://doi.org/10.1176/ ajp.147.1.83

National Institute for Health and Care Excellence (NICE). (2005). Post-traumatic stress disorder: Management. Clinical guideline. (Vol. cg26). London: National Institute for Health and Care Excellence.

Nickerson, A., Schick, M., Schnyder, U., Bryant, R. A., \& Morina, N. (2017). Comorbidity of Posttraumatic Stress Disorder and Depression in Tortured, Treatment-Seeking Refugees. Fournal of Traumatic Stress, 30(4), 409-415. http://doi. org/10.1002/jts. 22205

Nickerson, A., Steel, Z., Bryant, R., Brooks, R., \& Silove, D. (2011). Change in visa status amongst Mandaean refugees: relationship to psychological symptoms and living difficulties. Psychiatry Research, 187(1), 267-274. doi:10.1016/j. psychres.2010.12.015

Pabst, A., Gerigk, U., Erdag, S., \& Paulsen, G. (2013). Ein multiprofessionelles Behandlungsangebot für psychisch erkrankte Flüchtlinge [A multiprofessional treatment program for mentally ill refugees.] In: R. E. Feldmann \& G. H. Seidler (Eds.), Traum (a) 
Migration. Aktuelle Konzepte zur Therapie traumatisierter Flüchtlinge und Folteropfer. (pp. 115136). Gießen: Psychosozial-Verlag.

Palic, S., \& Elklit, A. (2009). An explorative outcome study of CBT-based multidisciplinary treatment in a diverse group of refugees from a Danish treatment centre for rehabilitation of traumatized refugees. Torture 19(3), 248-270.

Priebe, S., Giacco, D., \& El-Nagib, R. (2016). Public health aspects of mental health among migrants and refugees: $A$ review of the evidence on mental health care for refugees, asylum seekers and irregular migrants in the WHO European Region.

Richter, K., Lehfeld, H., \& Niklewski, G. (2015). Warten auf Asyl: Psychiatrische Diagnosen in der zentralen Aufnahmeeinrichtung in Bayern [Waiting for asylum: Psychiatric diagnosis in Bavarian admission center]. Gesundheitswesen, 77(11), 834-838. http://doi. org/10.1055/s-0035-1564075

Schauer, M., Neuner, F., \& Elbert, T. (2011). Narrative exposure therapy: $A$ short-term treatment for traumatic stress disorders (2nd ed.). Cambridge: Hogrefe Publishing \& Huber Publishing.

Schock, K., Böttche, M., Rosner, R., Wenk-Ansohn, M., \& Knaevelsrud, C. (2016). Impact of new traumatic or stressful life events on preexisting PTSD in traumatized refugees: results of a longitudinal study. European fournal of Psychotraumatology, 7(1), 32106. http://doi. org/10.3402/ejpt.v7.32106

Schweitzer, R., Melville, F., Steel, Z., \& Lacherez, P. (2006). Trauma, post-migration living difficulties, and social support as predictors of psychological adjustment in resettled Sudanese refugees. Australian and New Zealand fournal of Psychiatry, 40(2), 179-187. doi:10.1111/j.14401614.2006.01766.x

Selmo, P., Koch, T., Brand, J., Wagner, B., \& Knaevelsrud, C. (2016). Psychometric properties of the online Arabic versions of BDI-II, HSCL-25, and PDS. European fournal of Psychological Assessment, O(0), 1-9. http://doi. org/10.1027/1015-5759/a000367

Silove, D., Ventevogel, P., \& Rees, S. (2017). The contemporary refugee crisis: an overview of mental health challenges. World Psychiatry, 16(2), 130-139. http://doi.org/10.1002/wps.20438

Sjölund, B. H., Kastrup, M., Montgomery, E., \& Persson, A. L. (2009). Rehabilitating torture survivors. Fournal of Rehabilitation Medicine, 41(9), 689-696. http://doi.org/10.2340/16501977-0426

Slewa-Younan, S., Uribe Guajardo, M. G., Heriseanu, A., \& Hasan, T. (2015). A Systematic Review of Post-traumatic Stress Disorder and Depression
Amongst Iraqi Refugees Located in Western Countries. Fournal of Immigrant and Minority Health, 17(4), 1231-1239. http://doi.org/10.1007/ s10903-014-0046-3

Stammel, N., Knaevelsrud, C., Schock, K., Walther, L. C. S., Wenk-Ansohn, M., \& Böttche, M. (2017). Multidisciplinary treatment for traumatized refugees in a naturalistic setting: symptom courses and predictors. European fournal of Psychotraumatology, 8(sup2), 1377552. http:// doi.org/10.1080/20008198.2017.1377552

Steel, Z., Chey, T., Silove, D., Marnane, C., Bryant, R. A., \& van Ommeren, M. (2009). Association of torture and other potentially traumatic events with mental health outcomes among populations exposed to mass conflict and displacement: A systematic review and meta-analysis. $\mathcal{F} A M A$, 302(5), 537-549. http://doi.org/10.1001/ jama.2009.1132

Tabachnick, B. G., \& Fidell, L. S. (2001). Missing data. In B. G. Tabachnick \& L. S. Fidell (Eds.), Using multivariate statistics (pp. 62-72). Boston: Pearson Education.

Tinghög, P., Malm, A., Arwidson, C., Sigvardsdotter, E., Lundin, A., \& Saboonchi, F. (2017). Prevalence of mental ill health, traumas and postmigration stress among refugees from Syria resettled in Sweden after 2011: a populationbased survey. BMF Open, 7, e018899. http://doi. org/10.1136/bmjopen-2017-018899

UNHCR. (2016). Global Trends. Forced Displacement in 2015. http://www.unhcr.org/576408cd7.pdf

Weathers, F. W., Litz, B. T., Keane, T. M., Palmieri, P. A., Marx, B. P., \& Schnurr, P. P. (2013). The PTSD Checklist for DSM-5 (PCL-5). Bosten, MA: National Center for PTSD.

Wenk-Ansohn, M. (2017). Akutversorgung und traumaorientierte Langzeitbehandlung bei traumatisierten und psychisch belasteten Geflüchteten [Acute care and traumaoriented long-term treatment in traumatized and psychologically disstressed refugees]. In A. Liedl, M. Böttche, B. Abdallah-Steinkopf, \& C. Knaevelsrud (Eds.), Psychotherapie mit Flüchtlingen, Neue Herausforderungen, spezifische Bedürfnisse, das Praxisbuch für Psychotherapeuten und Ärzte (pp. 147-162). Stuttgart: Schattauer.

Wenk-Ansohn, M., Weber-Nelson, C., Hoppmann, F., \& Ahrndt, A. (2014). Behandlung und Rehabilitation von Folterüueberlebenden und Kriegstraumatisierten [Treatment and rehabilitation of torture survivors and individuals traumatized by war]. Psychosozial, 37(4), 55-74. 